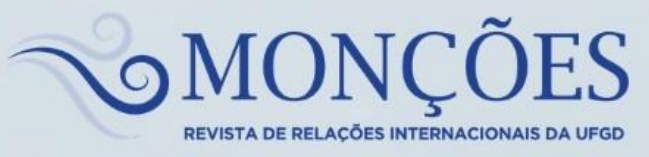

\title{
A SOBERANIA ALIMENTAR NO CONTEXTO DO REGIME ALIMENTAR NEOLIBERAL: um diálogo com a literatura
}

\section{LA SOBERANIA ALIMENTAR EN EL CONTEXTO DEL RÉGIMEN ALIMENTAR} NEOLIBERAL: un dialogo con la literatura

THE FOOD SOVEREIGNTY IN THE CONTEXT OF THE NEOLIBERAL FOOD REGIME: a dialogue with the literature

\author{
Nicole Figueiredo \\ International Policy Centre for Inclusive Growth (IPC-IG). \\ Brasília - Distrito Federal, Brasil \\ E-mail: nicolefigueiredo@hotmail.com.br \\ Orcid: https://orcid.org/0000-0002-6069-5364
}

Nilson Maciel de Paula Programa de Pós-graduação em Políticas Públicas, Universidade Federal do Paraná (UFPR). Curitiba - Paraná, Brasil E-mail: nilson@ufpr.br Orcid: https://orcid.org/0000-0002-2143-5172 
Resumo: Neste artigo é desenvolvido um diálogo com o conceito de regime alimentar. Ao resgatar seu viés histórico, a mutação de sua identidade é tratada de acordo com diferentes contextos nos quais a inserção das estruturas produtivas nacionais e respectivas relações comerciais são vistas de acordo com a evolução do capitalismo. Após a exposição dos traços definidores do primeiro regime, formado no final do século XIX e do segundo, vigente desde o pós II Guerra até início da década de 1970, esta revisão se concentra no regime alimentar neoliberal, ou terceiro regime. A dinâmica deste é, assim, adotada como referência essencial para o entendimento do fenômeno da insegurança alimentar, com evidências explícitas de desnutrição e obesidade em escala mundial, cuja superação tem sido um desafio crescente para governos e atores da sociedade civil. A literatura apresentada é dotada de uma abordagem histórica em suas vertentes política, social e econômica. Paralelamente, atenção é dada aos efeitos negativos da evolução do sistema alimentar no contexto do terceiro regime, e alinhado com a noção do desenvolvimento como liberdade. Mais ainda, a soberania alimentar é destacada como agenda necessária para políticas públicas orientadas pelos princípios do Direito Humano à Alimentação Adequada.

Palavras-chave: Regime alimentar; Neoliberalismo; Segurança e Soberania alimentar e nutricional.

\begin{abstract}
This paper contains a dialogue with the concept of food regime. Based on its historical principle, the changes undergone by its identity are treated in the light of different contexts, in which productive structures and related trade relations reflect the evolution of capitalism. After displaying the traces defining the first regime, taking form from the end of XIX century, and of the second, from the World War II to 1970s, this discussion focuses on the neoliberal regime also known as third regime. Its dynamics is, thus, adopted as a reference to grasp the phenomenon of food insecurity, as shown by evidence of malnutrition and obesity worldwide, which has challenged governments and actors of civil society. The literature here discussed follows a historical approach related to political, social e economic aspects. Simultaneously, attention is given to the negative events emerging from the food system in the context of the third regime, and, in line with the notion of development as freedom. Moreover, food sovereignty is brought to light as a necessary agenda for public policies oriented by the principles of human right to adequate food.
\end{abstract}

Keywords: Food regime; Neoliberalism; Food security and sovereignty.

Resumen: En este artículo desarrolla un dialogo con el concepto de Régimen Alimentar. Al rescatar su sesgo histórico, la mutación de su identidad es retratada de acuerdo a diferentes contextos en los cuales la inserción de las estructuras productivas nacionales y relaciones comerciales son vistas según la evolución del capitalismo. Después de la exposición de los rasgos definidores del primer régimen, construido en el fin del siglo XIX y del segundo régimen, vigente tras la II Guerra hasta principios de la década de 1970, esta revisión se enfoca en el régimen alimentar neoliberal, o tercer régimen. Su dinámica es adoptada como referencia esencial para el entendimiento del fenómeno de la inseguridad alimentaria, con evidencias explicitas de desnutrición y obesidad en escala mundial, cuya superación ha sido un desafío creciente para los gobernantes y actores de la sociedad civil. La literatura presentada es dotada de un abordaje histórico en sus vertientes política, social y económica. Paralelamente, atención es dada a los efectos negativos del sistema alimentar en el contexto del tercer régimen, y aliñado con la noción de desarrollo como libertad. Además, la soberanía alimentar es destacada como agenda necesaria para políticas públicas orientadas por los principios del Derecho Humano a la Alimentación Adecuada.

Palabras clave: Régimen Alimentar; Neoliberalismo; Seguridad y Soberanía Alimentaria. 


\section{CONSIDERAÇÕES INICIAIS}

Este artigo contém uma revisão da teoria dos regimes alimentares, na qual são resgatadas as características dos sucessivos regimes alimentares desde o final do século XIX quando o comércio internacional de alimentos conectava a produção de alimentos do hemisfério sul ao núcleo do capitalismo industrial nas grandes metrópoles do norte. Em especial, nesta análise a atenção está concentrada nas transformações ocorridas no sistema alimentar após a década de 1980, quando se formava uma ordem internacional sob os auspícios do neoliberalismo, na qual a dinâmica do sistema alimentar global passa a ser interpretada segundo os termos do regime alimentar neoliberal, ou corporativo. Um dos desdobramentos desse contexto é a propagação de um ambiente de insegurança alimentar, reflexo das desigualdades sociais e, em particular, do processo de precarização do mundo do trabalho, e do empobrecimento de dietas alimentares que se traduziram tanto na subnutrição quando na obesidade. Paralelamente, as políticas públicas orientadas pela austeridade fiscal e equilíbrio macroeconômico se tornaram incompatíveis com os pressupostos do desenvolvimento e da soberania alimentar, essenciais para conter os efeitos negativos das transformações recentes do sistema alimentar.

Segundo o conceito de regime alimentar, originalmente formulado por Friedmann \& McMichael (1989), o sistema alimentar global é interpretado através da conexão das relações internacionais de produção e consumo com as formas de acumulação dominantes em distintos contextos históricos do capitalismo, desde a década de 1870 (FRIEDMANN \& McMICHAEL, 1989). Sendo assim, após esta introdução, são destacados os traços estruturais dos regimes alimentares que se sucederam. Em seguida a análise se volta para o período posterior à década de 1970, quando, no contexto do capitalismo neoliberal, um novo regime emergiu sob o comando de grandes corporações transnacionais, traduzido pela noção de regime corporativo. Embora sujeito a interpretações díspares, tal regime é discutido no quarto tópico, no qual são também exploradas suas interfaces com diferentes manifestações da insegurança alimentar, intrínseca aos fenômenos da pobreza e da desigualdade. Frente a esse quadro, são discutidas perspectivas de reorientação do sistema alimentar através de iniciativas contra hegemônicas, capazes de revitalizar práticas produtivas e comerciais sintonizadas com os princípios da soberania alimentar. 


\section{O REGIME ALIMENTAR EM TRÊS ESTÁGIOS}

O sistema agroalimentar mundial passou por transformações profundas e persistentes desde meados do século XIX, em linha com o reordenamento político global nas relações internacionais sob um mutável quadro hegemônico, e com o processo geral de acumulação capitalista em suas sucessivas etapas. A noção pioneira de regime alimentar formulada por Friedmann \& McMichael (1989) tem sido amplamente reconhecida como ferramenta para a interpretação dessa evolução, de seus desdobramentos recentes, e suas perspectivas. No entanto, parafraseando o alerta feito por McMichael (2016b), essa noção não é uma construção teórica, mas um método histórico ou uma forma de análise das relações políticas, econômicas e ecológicas, envolvidas na produção e circulação mundiais de alimentos, segundo transformações periódicas do capitalismo mundial. Assim, além de demarcar três contextos históricos distintos, segundo sua concepção original, são caracterizados os momentos de transição do sistema capitalista mundial, nos quais as forças sociais fundantes dos regimes alimentares, determinam o modelo de produção e consumo alimentar e do comércio de alimentos (McMICHAEL, 2009a). Ademais, trata-se de uma abordagem interdisciplinar envolvendo economia, história, política, sociologia e direito, numa ótica que cobre esse tema em toda sua complexidade, na qual estão contemplados aspectos culturais e sociais (SODANO, 2012; McMICHAEL, 2009a). Bernstein (2016) chama atenção para a redefinição dos sucessivos regimes alimentares feita por MicMichael (2009b), como Projeto Colonial, Projeto de Desenvolvimento, e Projeto de Globalização, formulados por Estados e capitais. Mais do que uma revisão semântica, trata-se de expor o protagonismo de movimentos de resistência aos impactos destruidores causados pelas grandes corporações nos campos da agroecologia, da soberania alimentar, e das várias formas de diversidade, no contexto do regime corporativo, cujos desdobramentos têm produzido graves crises alimentares.

A evolução histórica embutida nessa abordagem reflete a ordem temporal definida por Braudel (1987), para quem não há rupturas totais entre passado e presente, uma vez que experiências passadas se prolongam, de forma que características de um regime alimentar não necessariamente desaparecem por completo, persistindo em circunstâncias posteriores. Neste sentido, percebe-se que os sistemas agroalimentares se transformam segundo a 
dinâmica do capitalismo, segundo um recorte temporal que começa com a ordem mundial marcada por extensivas relações coloniais a partir da hegemonia britânica, centro da economia mundial no século XIX, quando do primeiro regime alimentar. Essa inserção é explicitada por McMichael (2016a) ao afirmar que "o regime alimentar e a história do capital podem ser compreendidos como mutuamente condicionantes" (p.22). Ao longo do século XIX, antes mesmo de sua manifestação plena, os traços estruturais do primeiro regime alimentar já se manifestavam no comércio entre as metrópoles industrializadas e as colônias agroexportadoras. As relações de troca assim formadas refletiam o desequilíbrio econômico e político entre nações, como observado no caso do comércio de açúcar, cujo preço era determinado pelos principais polos de poder, o qual, orientado por fins políticos, está na base de determinado regime (McMICHAEL, 2016a, p. 41).

De acordo com Friedmann e McMichael (1989), o primeiro regime alimentar emergiu no período de 1870 a 1914, caracterizado pela importação europeia de alimentos e matérias primas, no interior de um sistema de Estados nacionais em formação, que preservava relações com as antigas metrópoles. Numa semântica distinta, (McMICHAEL, 2009b) apoiada em sua posição hegemônica, a Grã Bretanha se inseria no primeiro regime alimentar por meio de laços de dependência comercial de países agroexportadores, conectando zonas de abastecimento de alimentação barata situadas no hemisfério sul. Assim, a exploração das colônias servia para aumentar a riqueza britânica, via políticas mercantilistas numa divisão internacional do trabalho baseada no princípio ricardiano das "vantagens comparativas", na qual as colônias se especializaram em commodities alimentares e matérias primas, e a Grã-Bretanha em produtos industrializados. O baixo preço dos alimentos era determinado pela ampla disponibilidade de terras agricultáveis coloniais e pela oferta de mão de obra barata, proporcionando um barateamento dos salários no mundo industrializado (MCMICHAEL, 2016a). Ainda neste regime, a lógica capitalista até então era organizada localmente passa a ter uma dinâmica internacional, disseminando a acumulação extensiva no âmbito internacional, sob a égide do livre-comércio (PECHLANER \& OTERO, 2010).

Ao longo da primeira metade do século XX, o deslocamento do capitalismo em direção a um novo quadro hegemônico sob a liderança dos Estados Unidos, ensejava mudanças significativas no sistema alimentar e, portanto a configuração de um novo regime alimentar, 
assentado nas heranças criadas pelo capitalismo prévio à 1a Guerra Mundial (PECHLANER \& OTERO, 2010). Os escombros desse evento, aos quais se somou a fragmentação da economia mundial, não impediram que grandes capitais dessem um novo sentido ao sistema alimentar, para além das relações comerciais que predominaram em épocas pretéritas. A partir da $2^{\underline{a}}$ Guerra Mundial, impulsionado por uma estratégia de suporte à agricultura adotada pelo Estado norte-americano adotada desde a década de 1920, o sistema alimentar evoluiu sob o domínio das empresas processadoras de alimentos e atuantes na industrialização da agricultura (BURCH \& LAWRENCE, 2009). Tal transição não apenas deslocou o eixo do sistema global em torno das políticas comerciais e agroindustriais do novo hegemon, como converteu nações em desenvolvimento em espaços nos quais o modelo norte-americano de agroindustrialização se propagou, em particular através da Revolução Verde (MCMICHAEL, 2016a, p. 19).

Emergia assim o II Regime Alimentar, denominado regime de excedentes, tendo como base a hegemonia estadunidense, e a recuperação do livre comércio internacional sob seu comando (FRIEDMANN, 1993). Durante este período houve uma forte intervenção dos EUA no comércio agrícola internacional, não apenas controlando a instituição reguladora do comércio internacional sob o Acordo Geral de Tarifas e Comércio (GATT), após o malogro da Organização Internacional do Comércio, mas também subsidiando sua agricultura e causando um aumento expressivo de excedentes exportáveis. Para isso, contribuíram também programas de ajuda alimentar, a exemplo da PL480, que dava vazão aos excedentes via exportação a baixos preços ou por meio de ajuda humanitária, principalmente para países do Sul global (PECHLANER \& OTERO, 2010; PERREY, 2013). Esta opção buscava criar oportunidades e abrir mercados através de alianças num "império informal de Estados póscoloniais estratégicos no perímetro da Guerra Fria" (McMICHAEL, 2016a, p. 19), que em grande parte não tinham o trigo, a soja e o milho amarelo inseridos em sua dieta (FRIEDMANN, 1993).

Ao longo de 25 anos desse regime, países autossuficientes se tornaram dependentes de importação de alimentos, num comércio controlado por corporações internacionais atuantes em toda a extensão das cadeias produtivas, da produção de insumos agrícolas ao abastecimento. (PECHLANER \& OTERO, 2010). Enquanto no primeiro regime o alimento era 
importado pela nação então hegemônica, durante o segundo regime, sob a hegemonia estadunidense, o alimento foi incorporado nas estratégias geopolíticas como instrumento de poder, não apenas através das exportações de excedentes, e na pauta exportadora através da difusão de um modelo de produção e consumo a partir dos Estados Unidos. Ou seja, a "instrumentalização do alimento para assegurar a hegemonia global” (McMICHAEL, 2016a, p.15) foi utilizada de diferentes formas tanto no primeiro quanto no segundo regimes. Embora em ambos os casos a lógica do livre-comércio fosse amplamente disseminada, sua aplicação se deu de forma desigual, especificamente no caso do segundo regime, quando prevaleceu a política de descolonização estimulada pelos Estados Unidos para fins de expansão comercial, no bojo de processos de desenvolvimento nacional (McMICHAEL, 2016a). No entanto, a difusão das virtudes do livre-comércio pelas nações desenvolvidas se deparou com uma reviravolta no jogo competitivo internacional, quando países em desenvolvimento denominados NACs (New Agricultural Countries), a exemplo do Brasil e Argentina, emergiram como grandes exportadores de alimentos do complexo proteico. A partir daí, a agenda de liberalização comercial, sob o comando do GATT se deparou com uma persistente atitude protecionista, especialmente dos Estados Unidos, Japão e países europeus.

Mesmo não tratados no escopo do conceito de regime alimentar, é importante adicionar nesta revisão a importante contribuição de Goodman \& Redclift (1991), ao destacarem aspectos sociológicos da mudança nos hábitos alimentares, com destaque para o papel da mulher e para sua conexão com as mudanças tecnológicas, em particular no processamento de alimentos. As mudanças na divisão doméstica do trabalho e nos hábitos alimentares ao longo do século XX são vistos como aspectos estruturantes da evolução do sistema alimentar. Tais mudanças implicaram não apenas na maior presença da mulher no mercado de trabalho, mas também na propagação do hábito de comer fora e disseminação de lojas de fast-food, numa sinergia entre o trabalho das mulheres e a transformação mercantil e industrial dos alimentos. Além disso, outras razões contribuíram para mudanças nos hábitos alimentares no final do século XX, como aquelas na composição familiar (famílias menores), aumento na conscientização de hábitos saudáveis, conveniência como fator relevante às escolhas alimentares (menor tempo de preparo dos alimentos), e alimentação como reflexo dos padrões sociais (GOODMAN \& REDCLIFT, 1991). Essas mudanças foram fortemente 
determinadas pelo protagonismo das grandes corporações multinacionais, pela ampla desregulação do sistema econômico e financeiro sob a ordem neoliberal e pela expansão do comércio mundial, aspectos definidores do terceiro regime alimentar.

\section{TERCEIRO REGIME ALIMENTAR E O NEOLIBERALISMO}

Nos anos de 1970, com o colapso do regime de excedentes, ocorreram diversas manifestações, que somadas configuram o cenário de transição para o terceiro regime alimentar, num processo simultâneo ao esgotamento da lógica keynesiana (centrada no papel regulador do Estado e na execução de políticas de bem-estar social) avessa à centralidade do livre mercado, em particular na órbita financeira. Paralelamente, como expressão de uma tendência política e econômica internacional, formou-se um novo quadro hegemônico internacional, restringindo o protagonismo dos EUA, após a fragilização de sua economia e a desidratação do acordo de Bretton Woods. A evolução do capitalismo rumo a uma ordem neoliberal ${ }^{1}$, na qual a bipolaridade Estado/mercado se inverteu, é observada em todas as dimensões do sistema alimentar, redefinindo tanto sua dinâmica quanto sua rotulagem sob o comando das empresas transnacionais, cujos interesses globais estão no centro do terceiro regime alimentar (FRIEDMANN, 1993).

Embora as políticas neoliberais se deparem com condicionantes no âmbito interno de cada país, sua difusão internacional se deu mais livremente, impulsionada pelo movimento do capital financeiro e produtivo, e do comércio, sob a guarda de instituições multilaterais (MONBIOT, 2016). Assim é que medidas neoliberais foram adotadas com o propósito de superar a crise internacional de alimentos, dentre as quais a liberalização do comércio e aumento da produtividade agrícola, com maior uso de tecnologias de alto rendimento, e facilitação do mercado internacional de insumos agrícolas. Claramente, tais medidas acabaram reforçando o poder corporativo, a ideologia neoliberal e a própria financeirização deste mercado (SODANO, 2012).

\footnotetext{
${ }^{1}$ Neoliberalismo é definido aqui como uma "política ideológica segundo a qual o mercado e a eficiência produtiva, por meio da privatização, ampliam ao máximo o crescimento econômico, tendo como corolários o encolhimento do Estado e a abolição de contratos de trabalho e salvaguardas ambientais" (MCMICHAEL, 2016a, p. 214-215).
} 
Coerente com os propósitos herdados do GATT orientados pelo lema "One world, One Market", a postura oficial da Organização Mundial do Comércio (OMC) manteve as recomendações de que, através do livre comércio, crises de escassez num país seriam mitigadas por excedentes produzidos em outros. Esta premissa, todavia, esbarrou em decisões que contaminaram a própria essência daquelas instituições multilaterais, como observado primeiramente no Acordo Agrícola que fechou a Rodada Uruguai, e durante a claudicante Rodada Doha, quando barreiras tarifárias e não tarifárias, dumping e estímulo à produção doméstica, em particular nos EUA, UE e Japão prevaleceram sobre os princípios do livre comércio. Essa reversão no aparato regulatório multilateral, entretanto, não deturpou os princípios liberais das relações comerciais, cada vez mais complexas, tanto por uma extensa proliferação de acordos bilaterais e regionais, quanto pela prevalência de um padrão de comércio crescentemente intraindustrial, condições às quais o grande capital facilmente se adaptou (PAULA, 2017).

Outro aspecto estrutural do regime alimentar neoliberal a ser destacado diz respeito à importância da indústria de alimentos (MCMICHAEL, 2000; BURCH \& LAWRENCE, 2009), cujas atividades estão centradas na transformação industrial de produtos naturais, segundo a lógica do comércio intraindustrial sob o campando das grandes corporações (PAULA, 2017). Desta maneira, atenção se volta às práticas realizadas pela indústria de alimentos e a seus impactos nocivos no consumo alimentar, contribuindo para uma tendência de universalização dos padrões de consumo nos quais predominam alimentos processados e ultraprocessados. Sob os parâmetros formados no terceiro regime alimentar, a indústria alimentícia ganhou uma ampla capilaridade geográfica e capacidade para diluir os aspectos sazonais da alimentação, fazendo com que a distribuição de alimentos seja regular em todas as épocas do ano e em quase todos os territórios (NESTLE, 2013; PAULA, 2017). Entretanto, a grande abundância, a exemplo do que ocorre nos EUA, cuja produção alimentar tem sido suficiente para atender em quase duas vezes toda sua população, anda em paralelo com o aumento do consumo de calorias, agravando doenças relacionadas à supernutrição (NESTLE, 2013). Assim, a maior capacidade de produção e de inovação tecnológica não acompanha a necessidade de sanar a fome e a subnutrição, marcas intrínsecas ao sistema alimentar contemporâneo (PAULA, 2017). 
Paralelamente, a lógica financeira de acumulação avançou sobre o sistema alimentar, envolvido em todas as fases das cadeias produtivas, desde compra e venda especulativa de terras, conversão de alimentos em derivativos, aquisição de redes de abastecimento alimentar, etc (BURCH \& LAWRENCE, 2009). Por uma via semântica complementar Pechlaner e Otero (2010) caracterizam este regime pela redução do poder regulatório do Estado associada à maior proeminência do mercado, como observado na propagação em escala global de medidas neoliberais em todas as esferas da economia e da vida social. Esta lógica foi acolhida pela agenda das instituições multilaterais e inserida no modelo econômico dominante mundialmente, a partir da qual se disseminou um aprofundamento das desigualdades internacionais e concentração dos ganhos econômicos no mundo desenvolvido (PECHLANER \& OTERO, 2010; MCMICHAEL, 2016a). A roupagem financeira do terceiro regime alimentar pode ser também observada nos determinantes especulativos da crise alimentar de 2006, após banqueiros de Wall Street terem descoberto que alimentos poderiam, a exemplo de outros bens, ser convertidos numa abstração. Assim, a alimentação foi transformada num conceito através de um algoritmo agrupando gado, café, cacau, milho, trigo, e outros, num índice financeiro negociável (KAUFMAN, 2010). Esta é uma manifestação da influência do ideário neoliberal no mundo da alimentação, numa forte relação entre os sistemas alimentar e financeiro através da especulação capaz de transformar commodities alimentares em derivativos. No ano de 2000 este mercado girava em torno dos US\$ 5 bilhões, passando a US\$ 175 bilhões em 2007, sinalizando uma sinergia entre a crise financeira e a crise internacional de alimentos na mesma conjuntura (SODANO, 2012).

Tendo por base os termos do terceiro regime, tem-se que o acirramento da competição entre empresas não ocorre no mercado de seus produtos, mas pela disputa travada no campo financeiro e acionário (i.e., com maior retorno de investimento em menor tempo possível), pela especulação do preço dos alimentos, e pela diversificação de seu núcleo de negócios, em busca de maiores lucros e de controle da cadeia alimentar. Ou seja, as empresas estão inseridas numa estrutura de mercado cada vez mais oligopolista cuja dinâmica competitiva é definida globalmente (BURCH \& LAWRENCE, 2009). Imersos na financeirização dos mercados, os alimentos, em particular o milho, passaram a ter seus preços fortemente influenciados pelo mercado de combustíveis, reproduzindo uma estrutura de mercado e de competição 
semelhante ao que ocorre com o petróleo (McMICHAEL, 2009a). Além disso, os preços de alimentos ficaram ainda mais subordinados às poucas corporações controlando o mercado, tanto nas transações comerciais globais quanto na demanda por matérias primas alimentares, além de exercer forte influência nos hábitos alimentares da população, de acordo com suas estratégias de marketing e de expansão de mercado² (McMICHAEL, 2000).

Estes aspectos podem ser incorporados à definição de McMichael (2000) de regime alimentar corporativo, baseado na monocultura, em alimentos geneticamente modificados e na disseminação de uma dieta baseada em alimentos processados ${ }^{3}$. Por sua vez, a OMC contribui para a consolidação desse regime, ao disseminar os princípios do livre comercio em âmbito mundial (condicionada à correlação de forças no interior dessa instituição), via desregulação dos mercados, abertura para fluxos comerciais de investimento, entre outras medidas, que deixam o ambiente global de negócios mais propício à atuação de grandes empresas. Mais ainda, tais princípios neoliberais têm sido internalizados por nações através de privatizações de empresas estatais e ajustes macroeconômicos alinhados à prática de livrecomércio, condicionado às oscilações do Dólar, moeda hegemônica (McMICHAEL, 2016a).

Como dito acima, este regime emergiu em meio à crise do desenvolvimentismo e ao recuo do Estado como agente central na ordem econômica, cedendo espaço a um protagonismo crescente do mercado e das grandes corporações, reformando as estruturas institucionais de cada Estado nação, e redefinindo a lógica da divisão internacional do trabalho (McMICHAEL, 2000). Assim, a diversidade semântica para definir o terceiro regime (regime alimentar corporativo, regime alimentar neoliberal, etc), não diz respeito a visões subjetivas, mesmo que realçando aspectos distintos de um mesmo fenômeno. Mais do que isso, trata-se da interpretação da complexidade do sistema alimentar no contexto do capitalismo após a

\footnotetext{
2 Há de se notar que o controle destas corporações é estrutural, com incisivo controle sobre os preços, conforme conveniência.

${ }^{3}$ De acordo com a Organización Panamericana de la Salud (2015), e baseado em um conceito criado no Brasil, ultraprocessados são produtos com "formulaciones industriales elaboradas a partir de sustancias derivadas de los alimentos o sintetizadas de otras fuentes orgánicas [...] La mayoría de estos productos contiene pocos alimentos enteros o ninguno. Vienen listos para consumirse o para calentar y, por lo tanto, requieren poca o ninguna preparación culinaria [...] Estos alimentos son problemáticos para la salud humana por distintas razones: tienen una calidad nutricional muy mala y, por lo común, son extremadamente sabrosos, a veces hasta casi adictivos; imitan los alimentos y se los ve erróneamente como saludable; fomentan el consumo de snacks; se anuncian y comercializan de manera agresiva; y son cultural, social, económica y ambientalmente destructivos." (ORGANIZACIÓN PANAMERICANA DE LA SALUD, 2015, p.5-7).
} 
década de 1970, através da adaptação de ferramentas analíticas utilizadas para compreender contextos históricos prévios e suas transições. A reformulação terminológica não indica um esvaziamento da noção de regime alimentar, mas reflete a amplitude do debate sobre as novas condições em que os alimentos são produzidos, comercializados e consumidos.

Por isso, a revisão crítica por Bernstein (2016) sugerindo uma "campezinização" do conceito de regime alimentar é uma tentativa de introduzir parâmetros externos à sua essência interpretativa. A leitura de Bernstein é contestada por McMichael (2016b) ao recuperar a trajetória desse conceito numa contínua reformulação em linha com as contradições e conflitos imersos na nova ordem alimentar, marcada por uma disseminada influência dos princípios liberais no ideário político e dos fluxos internacionais de capital nas transformações do sistema alimentar. Como destacado por Pritchard (2009), apud McMichael (2016b), tal conceito contribui para organizar a complexa realidade das estruturas políticas globais da alimentação, e desvendar os desdobramentos futuros da dinâmica atual do sistema alimentar. Por sua vez, Friedmann (1993) já havia aberto os flancos do conceito ao discutir a transição do segundo para o terceiro regime, quando os excedentes da nação hegemônica se convertiam em escassez, e a regulação do comércio retrocedia rumo a ameaças reiteradas de guerra comercial, em particular entre EUA e UE (Atlantic Pivot) numa versão moderna de mercantilismo, com suporte de preços, subsídios e dumping comercial, em pleno capitalismo neoliberal. Naquele contexto, as corporações transnacionais romperam a moldura regulatória nacional ampliando as bases globais do sistema agroalimentar e, por conseguinte, a sinergia mercantil industrial do segundo regime, sem confrontar aquelas práticas protecionistas.

Em seu diálogo com as críticas de Bernstein (2016), Friedmann (2016) reafirma a consistência da abordagem de regime alimentar, mas realça a eventualidade de um embate entre as forças hegemônicas das corporações e os movimentos sociais em prol da soberania alimentar e da defesa do meio ambiente. Projeta-se assim um sistema alimentar sob o comando do grande capital, ou reformatado pelos agricultores segundo uma agenda que esgotaria o sentido do regime corporativo. Dessa forma, o regime alimentar, enquanto abordagem analítica implica na inclusão de outras dimensões à dinâmica do capital, as quais evitam perspectivas de uma ruína fatal do sistema alimentar no futuro. 
A consistência da abordagem de regime alimentar está, ademais, amparada na convergência entre Friedmann e McMichael, ao reconhecerem a importância das dimensões locais e dos movimentos sociais engajados nas perspectivas de conter as bases hegemônicas da ordem global. Daí a necessidade de incluir questões relacionadas à segurança e soberania alimentar nessa revisão. Já em seu artigo pioneiro destacavam que a transição do sistema alimentar na esteira da crise do segundo regime requereria uma nova regulação dos processos globais de acumulação e uma nova disciplina do padrão monetário internacional, simultaneamente a uma reformatação da ordem alimentar com base em estratégias que reconectem a produção e consumo no âmbito local.

Nessa perspectiva, em que pese uma profusão de críticas à noção de regime alimentar (NIEDERLE, 2017), em particular aquelas realçando sua generalização de uma ordem alimentar global, desconsiderando a heterogeneidade social em suas particularidades locais, subsequentes adaptações foram incorporadas ao emprego daquele conceito para análises das transformações recentes no sistema alimentar. Nesses termos, em consonância com os propósitos deste artigo, o escopo de questões tratadas no contexto do terceiro regime se ampliou a ponto de incorporar as repercussões destruidoras das forças hegemônicas no meio ambiente, na soberania alimentar dos povos, assim como o protagonismo de movimentos sociais antagônicos.

A noção de regime alimentar corporativo representa assim uma conjuntura da agricultura mundial (período equivalente a cerca de 40 anos), reorganizada pelo neoliberalismo, dentro da longue durée do capitalismo (período superior a 100 anos), de acordo com a lógica de Braudel. Isso implica dizer que este regime não deve ser visto como um processo linear, uma vez que conjunturas são temporárias (McMICHAEL, 2009a). Ainda assim, embora não seja claro como irá se desenrolar, o arcabouço analítico do terceiro regime alimentar abarca aspectos contraditórios relacionados à origem dos alimentos ao realçar a sobreposição das dimensões globais da alimentação (food from nowhere), e das bases sociais e agroecológicas locais (food from somewhere). Da mesma forma, McMichael (2005) já destacava a voracidade e amplitude do poder corporativo, respaldado por regras institucionais do livre comércio, ou complacentes com subversões recorrentes, comprometidas com a abertura dos mercados ao grande capital. Como resultado, a agricultura mundial se constitui pela apropriação de 
recursos (land grabbing), integrando circuitos comerciais e desconectando o uso da terra do consumo alimentar para favorecer o processamento industrial e produção de energia. De forma complementar, este regime se manifesta no interior do sistema produtivo e comercial e nas relações socioculturais das sociedades, através de sistemas alimentares locais, nos quais estruturas produtivas tradicionais lutam para sobreviver em meio às estratégias destrutivas do grande capital e seus mercados globalizados. Portanto, é preciso considerar que o terceiro regime alimentar se depara com conflitos e contradições inerentes à dinâmica geral de acumulação capitaneada por corporações transnacionais atuantes em toda a extensão do sistema alimentar.

\section{AS CONTRADIÇÕES DO TERCEIRO REGIME E A CENTRALIDADE DA INDÚSTRIA}

A formação de uma ideia de alimento como mercadoria e produto da industrialização gerou diversos contra movimentos, os quais, apesar de suas diferentes origens, se unificam em torno de iniciativas como agricultura orgânica e comunitária (McMICHAEL, 2000). Esse movimento contra hegemônico tem sido reforçado por políticas nacionais e locais de segurança alimentar, e tem também contribuído para resgatar a harmonia entre agricultura e a natureza e os vínculos mercantis no interior de circuitos comerciais locais. Friedmann (1993) já ressaltava o papel dessa organização alternativa da agricultura para reconstruir a diversidade, o uso consciente da terra como uma expressão cultural e a dignificação do trabalho no campo. Com isso, nem a suposta uniformidade da ordem alimentar da globalização neoliberal, nem a oposição binária entre o capital agroindustrial e a diversidade do campesinato, ou a tese e antítese segundo Bernstein (2016), são valorizadas como referências para a discussão aqui realizada. Diferentemente, movimentos contra hegemônicos que possuem na ecologia, no meio ambiente e nas organizações alternativas de mercado, suas expressões mais características, são manifestações das contradições internas ao terceiro regime. Como contra argumenta McMichael (2016b), o regime corporativo não está assentado numa relação binária capital/campesinato, mas em determinantes nos quais esses opostos, vistos como categorias historicamente constituídas, interagem no conflito implícito à commodity alimento. 
Como parte dessa relação conflituosa, a agenda do alimento saudável e da segurança alimentar se tornou um campo de disputa entre narrativas e estratégias distintas, sem que um cenário totalizante seja previsível. Se por um lado não é possível supor que políticas neoliberais e um ambiente de livre mercado promovam segurança alimentar, por outro a concretização desta agenda não depende apenas do monopólio do campesinato, através de um sistema alimentar alternativo. Diante desse embate, é improvável que as instituições atualmente dominantes neste regime alimentar tragam soluções sustentáveis para suas próprias contradições sócio-ecológicas de forma suficientemente ampla para conduzir as estruturas numa outra direção. Prováveis soluções para os efeitos negativos deste regime virão das reflexões voltadas para o fortalecimento de estratégias de soberania alimentar em suas distintas vertentes (McMICHAEL, 2009a), e do ativismo de movimentos sociais visando uma reorientação do regime alimentar de baixo para cima (PECHLANER \& OTERO, 2010).

Segundo a visão neoliberal, o estado de segurança alimentar depende da incorporação de agricultores locais ao mercado global, através da livre concorrência (FRIESEN, 2017). Nesta lógica, o Estado deve ser mínimo, as esferas sociais e políticas desligadas do âmbito econômico (SODANO, 2012), e os serviços púbicos privatizados. Este recuo do Estado, somado à precarização dos serviços públicos, torna-se a via pela qual ocorre a privatização dos direitos (MONBIOT, 2016), dentre os quais o direto a uma alimentação adequada. Desta forma, a impossibilidade de promover segurança alimentar em nível mundial reflete a dinâmica do regime alimentar neoliberal (SODANO, 2012; FRIESEN, 2017; PERREY, 2013), em cujo contexto o número de pessoas em estado de insegurança alimentar tem aumentado, simultâneo ao aumento do desperdício de alimentos e da desigualdade de renda.

Tendo como referência o período recente, além da fome e subnutrição, o sentido da insegurança alimentar passou a incorporar as condições de sobrepeso e obesidade, resultantes do maior consumo de produtos industrializados, e agravadas pela pobreza, baixo nível educacional e precarização dos hábitos de consumo definidos sob a dieta neoliberal fortemente influenciada pela indústria alimentar (SODANO, 2012). Neste sentido, o neoliberalismo não prevê qualquer forma de intervenção visando manter os direitos a uma alimentação adequada e segura, na medida em que as estruturas de poder vigentes perpetuam a insegurança alimentar como um fenômeno de dimensões globais. Como 
decorrência da centralidade da indústria no terceiro regime, estratégias de marketing e publicidade se tornaram ferramentas poderosas para expansão do espaço comercial dos produtos e aumento do consumo para além das necessidades nutricionais dos consumidores. Para tanto, movidas pelos desafios competitivos e necessidade de ampliação de mercado, as empresas da indústria alimentar estimulam o aumento do consumo, ao mesmo tempo em que novas versões de determinadas marcas, e novos produtos acabam gerando novas demandas. Essas empresas investem cerca de 50 vezes mais em publicidades do que aquelas que recomendam dietas saudáveis, enquanto financiam o lobby que os beneficiem no âmbito da pesquisa científica e dos espaços políticos, manipulando o consumidor e criando uma falsa impressão de liberdade de escolha por gosto pessoal, conveniência e preço (NESTLE, 2013). Com isso, novos hábitos alimentares somados à mudança das práticas agropecuárias têm afetado a saúde humana quando doenças crônico-degenerativas (diabetes, obesidade, doenças cardiovasculares, câncer, entre outras), se tornaram as principais causas de mortalidade (VALENTE, 1997). Estas são consequências de um sistema alimentar moderno que por meio de uma dieta heterogênea, modifica negativamente a saúde e a qualidade de vida das pessoas (AZEVEDO \& RIGON, 2017).

Como sugere Nestle (2013), a dieta alimentar se torna, portanto, uma questão política, não apenas dos movimentos sociais, mas também das decisões governamentais em resposta aos interesses de empresas vis a vis o interesse público, num conflito permeado pela sobreposição do preço dos alimentos ao valor nutricional e a qualidade dos alimentos. Desde os anos de 1960, a modernização dos meios de produção na agricultura foi considerada uma estratégia para acabar com a fome, aumentando a produção por meio de insumos químicos, como se a falta de alimentos fosse o fator que justificasse a fome. Esta relação se revelou infundada, já que o problema da fome persiste atualmente e está relacionado à insuficiência de renda e não a limitações de oferta (BREILH, 2016; RIGON \& BÓGUS, 2016), tendo em vista que esta tem aumentado paralelamente ao aumento da fome (SEN, 1995). De fato, a industrialização da agricultura desde então gerou um aumento do número de pessoas em situação de insegurança alimentar (RIGON \& BÓGUS, 2016). Para tratar das questões envolvidas na contradição entre acesso limitado a uma alimentação adequada e o excesso de alimentos, é essencial também levar em conta as dinâmicas de poder, tanto em nível local 
quanto internacional (KEPPLE \& SEGALL-CORRÊA, 2011). Apesar das diferentes vias de propagação dessas tendências, as respostas para o problema da insegurança alimentar e da fome em particular estão situadas prioritariamente no âmbito local.

\section{A INSEGURANÇA ALIMENTAR NO TERCEIRO REGIME E A RELEVÂNCIA DA SOBERANIA ALIMENTAR}

A crise alimentar de 2007 deixou mais de um bilhão de pessoas em nível mundial passando fome, a maioria delas em países da África, Ásia e América Latina. Mesmo que este número tenha reduzido nos anos posteriores, em nenhum momento chegou a níveis inferiores a 600 mil, chegando em 2017 a um contingente populacional de 663 mil pessoas nesse estado, segundo dados da Organização das Nações Unidas para Alimentação e Agricultura (FAO). Além disso, naquele ano, 8,8\% da população mundial estava em estado de subnutrição, definido pela ingestão de calorias insuficientes para atender ao dispêndio de energia necessário por um indivíduo. Este quadro se formou simultaneamente à apropriação dos recursos produtivos pelo capital e do subsequente poder de mercado que sujeita agricultores e consumidores à mercantilização excessiva dos alimentos segundo uma falsa lógica da eficiência dos mercados, os quais, na verdade, corroem a segurança alimentar, a saúde pública e meio ambiente. Destaque-se, todavia, que a insegurança alimentar, especialmente a fome, não é um traço típico apenas da ordem alimentar que emergiu no contexto do terceiro regime, como se observa nas milhões de mortes causadas pela fome em pleno vigor do capitalismo liberal do final do século XIX (DAVIS, 2003). Igualmente, a fome que afetou milhões no rescaldo do pós 2a Guerra Mundial motivou a percepção geopolítica do novo hegemon colocando o alimento no centro da nova ordem mundial a ser construída e pavimentando o caminho para a difusão de um modelo de produção e consumo através da campanha "Alimentos para a Paz".

À luz da dinâmica do sistema agroalimentar, "a noção de insegurança alimentar passa a estar associada a uma ampla diversidade de aspectos físicos, nutricionais, socioeconômicos, ambientais, culturais, etc." (PAULA, 2017, p. 174). Da mesma forma, de acordo com Sen (2000), a proteção contra a fome, a ser garantida pelo Estado, deve ser vista como ingrediente do desenvolvimento como liberdade, de forma que mecanismos de proteção social são fundamentais, para evitar que, em momentos de crise, os mais vulneráveis sejam atingidos. A 
renda é um dos fatores de maior importância para garantir que os indivíduos tenham plenas capacidades para desenvolver seu potencial, uma vez que uma renda baixa pode ser um fator de privação, já que são necessários níveis mínimos de poder de compra para evitar a fome; e educação básica e saúde, uma vez que estes também são serviços que melhoram a qualidade de vida, assim como elevam o potencial para aumentar sua renda e suas capacidades (SEN, 2000). Neste mesmo sentido, em 1996, a FAO reconheceu a pobreza como fator determinante da fome, e que em consequência disso, a própria fome seria o fator que impede que estes possam romper os limites da pobreza a que estão submetidos (PAULA, 2017).

Esta é, todavia uma situação complexa, cuja solução implica em reconhecer que a fome deriva de uma diversidade de fatores, como inundações, secas, inflação, desemprego, entre outros, mas essencialmente da desigualdade. Assim é que diferentes camadas da sociedade vivem de forma diferente os efeitos da insegurança alimentar, o que faz com que o Estado trate diferentemente seus efeitos (SEN, 1995), de forma que a própria percepção da subnutrição dificulta seu diagnóstico, bem como a formulação de soluções. A

\footnotetext{
subnutrição pode ser consequência de pouca, assim como de muita comida, de uma combinação inadequada de alimentos com nenhum ou baixo valor nutricional, ou ainda do consumo de alimentos contaminados [...] indicando as várias faces do estado de insegurança alimentar (PAULA, 2017, p. 167-168).
}

Ainda sobre as causas da fome, o comércio mundial de alimentos no contexto do regime alimentar neoliberal evoluiu sob o comando de grandes corporações, cujos tentáculos se estendem às relações de consumo, nas quais se destacam grandes produtores conectados com o circuito da financeirização dos alimentos. Este movimento ocorre em detrimento das culturas alimentares tradicionais que valorizam a base camponesa e familiar, voltadas aos mercados locais. Ou seja, a ordem hegemônica dos mercados globais não é capaz de superar o quadro de fome, insegurança, precarização do trabalho e desemprego (LIMA, 2018). Neste sentido, na contramão da tendência do comércio internacional de alimentos, ganha relevância a produção de alimentos para subsistência, ainda mais quando é possível uma produção diversificada, já que não dependendo dos grandes mercados, da variação da oferta e/ou dos 
preços (SEN, 1995). A autonomia alimentar, portanto, é factível, o que pode também ser interpretado como soberania alimentar.

Assim, é preciso observar a existência de sistemas alimentares alternativos no interior do regime alimentar corporativo hegemônico, os quais se formaram em sintonia com o conceito de soberania alimentar ${ }^{4}$, elaborado pela Via Campesina em decorrência de seu ativismo durante a crise agrária derivada de políticas neoliberais em 1993, congregando organizações representativas do campesinato de mais setenta países (McMICHAEL, 2016a).

\begin{abstract}
Políticas neoliberais dão prioridade ao comércio internacional, e não a alimentos para a população. Não contribuíram em nada com a erradicação da fome no mundo. Pelo contrário, aumentaram a dependência dos povos por importações agrícolas e fortaleceram a industrialização da agricultura, assim colocando em risco a herança genética, cultural e ambiental de nosso planeta, bem como nossa saúde. Forçaram centenas de milhões de agricultores ao abandono de suas práticas agrícolas tradicionais, ao êxodo rural ou à emigração (VIA CAMPESINA, 2003, apud McMICHAEL, 2016a, p. 85).
\end{abstract}

De acordo com Edelman et al (2014) a soberania alimentar é um conceito em construção, sua complexidade se dá por se tratar de um processo dinâmico e multidimensional. Trata-se de corrigir as precariedades do trabalho no campo, revalidando estes ambientes e estilos de vida, através da luta por terra, sementes, economias rurais saudáveis, sustentáveis e diversificadas, educação, representação, mercados incorporados e conexões globais, regionais e locais mais justas. Frequentemente este conceito também é adotado como um conjunto de demandas, princípios, políticas, reformas e direitos, que contestam o regime alimentar neoliberal, mas que ao mesmo tempo devem ter maior atenção às mudanças necessárias que devem ocorrer no sistema capitalista e no modelo de Estado atualmente vigente.

Dentre as propostas abordadas pela Via Campesina, está o fomento a mercados locais descentralizados e práticas agrícolas sustentáveis, fortalecimento de emprego na área rural, defesa da biodiversidade, voltadas aos mercados domésticos, de forma a fortalecer "práticas

\footnotetext{
${ }^{4}$ Explicitado na Declaração de Nyélény, após o Fórum Mundial para a Soberania Alimentar. Disponível em: <https://nyeleni.org/spip.php?article327> Acesso em: 24/07/21.
} 
culturais que não reduzam o alimento e a agricultura à formulação de preços" (MCMICHAEL, 2016a, p. 86), não reduzindo a alimentação a aspectos exclusivamente mercadológicos. Dessa forma, soberania alimentar se torna cada vez mais relevante à medida que o modelo econômico hegemônico globaliza o sistema alimentar e a própria alimentação, tendo como referência o Direito Humano à Alimentação Adequada (DHAA), cujo escopo vai além dos aspectos sanitários e puramente biológicos do alimento. Nesse contexto, o DHAA emergiu através de uma narrativa contestadora das tendências dominantes, cada vez mais associada às iniciativas contra hegemônicas.

Em contraposição às tendências dominantes do terceiro regime alimentar, o comércio internacional deve estar a serviço da segurança alimentar, sujeito à existência de estoques reguladores de forma a reduzir a volatilidade dos preços, e a vulnerabilidade de países dependentes de importação, desvinculando as políticas nacionais de abastecimento dos mercados globais. (FRIESEN, 2017; ROSSET \& MARTINEZ, 2014). Paralelamente, o caminho para combater a fome e suas causas seria o do desenvolvimento econômico local, valorizando a produção local e criando circuitos locais de comércio, ativando a circulação monetária, e fazendo com que o alimento tenha preço justo ao produtor e ao consumidor, ao invés de submeter a alimentação à lógica financeira e às estratégias das grandes corporações. 0 neoliberalismo e o livre comércio são, dessa forma, nocivos à soberania alimentar, principalmente por exporem produtores a uma competição global, ao mesmo tempo em que manobras comerciais de proteção e incentivos que destoam dos princípios liberais, são camufladas, penalizando agricultores de países periféricos (ROSSET \& MARTINEZ, 2014).

Embora a agenda contra-neoliberal de segurança alimentar ainda seja utópica, diante da hegemonia do modelo neoliberal, é importante conceber um modelo operacional de sociedade politicamente aceitável (SODANO, 2012). Para tanto são necessárias propostas capazes de superar situações como a ocorrida em 2008, quando da crise financeira, e com ela uma oportunidade de mudança do sistema vigente. As dificuldades de desenho de caminhos alternativos ao sistema capitalista, associadas àquelas relacionadas à necessidade de mudar as estruturas de poder econômico e político, têm dado sobrevida à lógica neoliberal (MONBIOT, 2016). Ainda assim, de acordo com Friesen (2017), é necessário que o conceito de soberania alimentar preserve seu caráter transformador, impedindo que seja apropriada 
pelo paradigma neoliberal e impulsionando mudanças estruturais no sistema alimentar. Moldado pela proeminência das grandes corporações, o sistema alimentar vigente se revela insustentável e incompatível com os princípios do DHAA e de preservação dos recursos naturais, o que tem estimulado a busca por alternativas para reverter seus inevitáveis efeitos negativos. Essa busca deve envolver noções de democracia participativa e do alimento como um direito humano, se contrapondo às propostas de segurança alimentar neoliberais através da reorganização do comércio de alimentos e da reforma agrária (SODANO, 2012).

\section{CONSIDERAÇÕES FINAIS}

A teoria dos regimes alimentares permite enxergar as diversas relações entre a história política mundial e as interações das estruturas agroindustriais com os padrões de consumo alimentar. Ao enfatizar o período a partir do final da década de 1970, quando as políticas neoliberais ganharam forte proeminência, foram explicitados os ingredientes centrais do arcabouço teórico hegemônico, à luz da qual as políticas públicas alimentares devem ser analisadas. Na história dos regimes alimentares e também do capitalismo, nenhum dos modelos de desenvolvimento adotados possibilitou a superação da fome e de outros problemas relacionados às carências alimentares, já que são paradigmas que valorizam mais os fins que os meios, i.e., modelos econômicos que tenham como fim o crescimento econômico, baseado na precarização das relações de trabalho. Com isso, a fome é consequência da exploração econômica e social, um reflexo da falta de justiça social e da negação de direitos, já que a questão alimentar transborda o aspecto nutricional, envolvendo dimensões relacionadas à dignidade humana, saúde física e mental (VALENTE, 1997). No terceiro regime alimentar esta tendência tem se acentuado, quando as estratégias de segurança alimentar se tornaram menos promissoras e mais frágeis. Mesmo assim, utilizouse como referência o debate sobre soberania alimentar como saída necessária para combater os efeitos negativos desse regime, na expectativa de que os povos possuam o direito de se alimentar de forma saudável e culturalmente apropriada, amparados em sistemas alimentares locais e sustentáveis. Vistas segundo uma visão contra hegemônica, estas estratégias são essenciais para restringir a lógica dominante no sistema agroalimentar. Levando sempre em conta que para se compreender o mundo da alimentação, os quais se mostram extremamente 
complexos e multidisciplinares, é importante relativizar as questões econômicas e questionar a neutralidade dos mercados, assim como das políticas governamentais.

\section{REFERÊNCIAS}

AZEVEDO, Elaine \& RIGON, Silvia do Amaral. Soberania alimentar com base no conceito de sustentabilidade. In: TADDEI, J.A.; LANG, R.M.F.; TOLONI, M.H.A. (Org.) Nutrição em Saúde Pública. Rio de Janeiro: Editora Rubio, 2017.

BERNSTEIN, Henry. Agrarian Political Economy and Modern World Capitalism: the Contributions of Food Regime Analysis. International Institute of Social Studies (ISS). The Hague, The Netherlands. 2016.

BRAUDEL, Fernand. A dinâmica do capitalismo. Tradução: Álvaro Cabral. Rio de Janeiro, Rocoo, 1987.

BREILH, Jaime. Hacia una redefinición de la soberanía agraria: Es posible la soberanía alimentaria sin cambio civilizatorio y bioseguridad? In: BEZERRA, I.; PEREZ- CASSARINO, J. (Org.) Soberania Alimentar (SOBAL) e Segurança Alimentar e Nutricional (SAN) na América Latina e Caribe. Curitiba: Editora UFPR, 2016. P. 55 - 68.

BURCH, David \& LAWRENCE, Geoffrey. Towards a third food regime: behind the transformation. Agricultural Human Values, no 26, pg. 267 - 279, 2009.

DAVIS, Mike, 0 genocídio da grande fome do século 19, in Le Monde Diplomatique, $<$ https://diplomatique.org.br/o-genocidio-da-grande-fome-do-seculo-19/>, 2003. Acesso em: 14 de junho de 2021.

EDELMAN, Marc; WEIS, Tony; BAVISKAR, Amita; SATURINO, M. Borras Jr.; HOLT-GIMÉNEZ, Eric; KANDIYOTI, Deniz; WOLFORD, Wendy. Introduction: critical perspectives on food sovereignty. The Journal of Peasant Studies. London, UK, 2014.

FRIEDMANN, Harriet \& MCMICHAEL, Philip. Agriculture and the state system: The rise and decline of national agricultures, 1870 to the present. Sociologia Ruralis, Vol. XXIX-2, 1989.

FRIEDMANN, Harriet. The political Economy of Food: a global crisis. New Left review, no 197: pg. 29-57. Janeiro, 1993.

Food Regime Analysis and Agrarian Questions: Widening the Conversation. International Institute of Social Studies (ISS). The Hague, The Netherlands. 2016. 
FRIESEN, Laura Dawn. The failures of neoliberal food security and food sovereignty alternative. University of Saskatchewan Undergraduate Research. Journal, Volume 4, Issue 1, 2017.

GOODMAN, David \& REDCLIFT, Michael. Refashioning Nature: Food, Ecology and Culture. Ed. Routledge, 1991. Cap 1: Food into freezers: women into factories.

KAUFMAN, Frederick. (2010) How Wall Street starved millions and got away with it, Harper's Magazine.

KEPPLE, Anne Walleser \& SEGALL-CORRÊA, Ana Maria. Conceituando e medindo Segurança Alimentar e Nutricional. Ciência \& Saúde Coletiva, 16(1):187-199, 2011.

LIMA, Marcos Costa. Segurança Alimentar e as Sistemáticas Contradições do Capitalismo. Revista Jornalismo e Cidadania. No 21, março de 2018, pg. 12-13.

McMICHAEL, Philip. The power of food. Agriculture and Human Values no17 p. 21-33, 2000.

A food regime analysis of the 'world food crisis', Agricultural Human Values, no29 p. 281-295, 2009a.

. Banking on agriculture: A review of the World Bank's World Development Report 2008. Journal of Agrarian Change 9, no. 2: 235-46, 2009b.

Regimes alimentares e questões agrárias. Estudos Camponeses e Mudança Agrária. Tradução: Sonia Midori. São Paulo; Porto Alegre: Editora Unesp e Editora UFRGS. 1o ed., 2016a.

BERNSTEIN-MCMICHAEL-FRIEDMANN DIALOGUE ON FOOD REGIMES; Commentary: Food regime for thought, The Journal of Peasant Studies, Vol. 43, no. 3: 648670,

MONBIOT, George. Neoliberalism - the ideology at the root of all our problems. 2016.

Disponível em: <https://www.theguardian.com/books/2016/apr/15/neoliberalism- ideologyproblem-george-monbiot> Acesso em: 15 Jul. 2019.

NESTLE, Marion. Food Politics: how the food industry influences nutrition and health. Introduction: The Food Industry and "Eat More". 2013.

NIEDERLE, Paulo A. A pluralist and pragmatist critique of food regime's genealogy: varieties of social orders in Brazilian agriculture. Journal of Peasant Studies, pgs 1460-1483, Jun. 2017. 
ORGANIZACIÓN PANAMERICANA DE LA SALUD (OPS). Alimentos y bebidas ultraprocesados en América Latina: tendencias, efecto sobre la obesidad e implicaciones para las políticas públicas. Washington, D.C. 2015.

PAULA, Nilson Maciel de. Evolução do sistema agroalimentar mundial: contradições e desafios. Curitiba: CRV, 2017.

PECHLANER, Gabriela \& OTERO, Gerardo. The neoliberal food regime: neoregulation and the new division of labor in north America. By the rural sociological society, volume 75, $p$. 179 - 208, junho de 2010.

PERREY, Shoshana Devra. Food Regimes, Race and The Coloniality of Power: Linking histories in the food sovereignty movement. Conference paper for discussion at: Food sovereignty movement, a critical dialogue. International Conference Yale University, Conference Paper \#52. September 14-15, 2013.

RIGON, Silvia do Amaral \& BÓGUS, Cláudia Maria. A Segurança alimentar e nutricional: das concepções norteadoras ao início dos processos de consolidação. In: BEZERRA, I.; PEREZCASSARINO, J. (Org.) Soberania Alimentar (SOBAL) e Segurança Alimentar e Nutricional (SAN) na América Latina e Caribe. Curitiba: Editora UFPR, 2016. P.31 - 54.

ROSSET, Peter \& MARTINEZ, Maria Elena. Soberanía: reclamo mundial. In: Ecofronteras, 2014, vol.18, n. 51, pp.8-11.

SEN, Amartya. Desenvolvimento como liberdade. Companhia das Letras. São Paulo, 2000.

Food, Economics, and Entitlements. In: DRIZE, J.; SEN, A.; HUSSAIN, A.. The Political Economy of Hunger - Selected Essays. Clarendon Press, Oxford, 1995.

SODANO, Valeria. Food Policy Beyond Neo-Liberalism. Sociological Landscape - Theories, Realities and Trends. Março de 2012.

VALENTE, Flávio Luiz Schieck. Do combate à fome à Segurança Alimentar e Nutricional: o direito à alimentação adequada. R. Nutr. PUC camp., Campinas, 10(1): 20-36, jan/jun, 1997. 